Capybaras, reproduced from Brehm's Thierleben of 1877 in Lynn Barber's book. In the mid-19th-century domestication of wild life for food was widely discussed and practised, and capybaras were recommended as 'converting into wholesome nutriment vegetable substances which are turned to no account.'

Today, experiments in domesticating these large South American rodents are again being tried

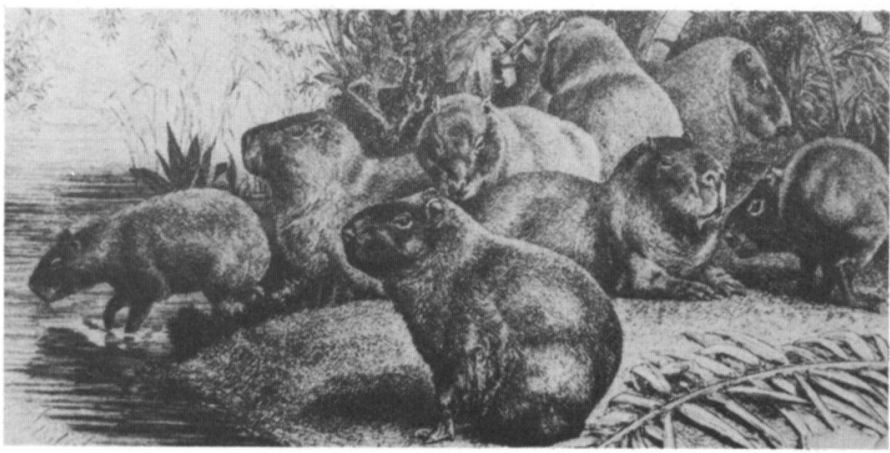

naturalists who were interested in invertebrates still followed Linnaeus in classifying them all as either insects or worms. If Paley had not stimulated so much research and general interest, in the way Lynn Barber so readably describes, the followers of White might have remained a tiny sect until the end of the century, and the heyday might have been postponed until our own day.

RICHARD FITTER

\title{
The Secrets of the Blind Dolphins, by Giorgi Pilleri. Sind Wildlife Management Board, \$25.
}

The conclusions drawn at the end of this book are pre-empted in an early chapter in which Professor Pilleri states: 'There can be no doubt that this species is in serious danger of becoming extinct, even if its disappearance will be of little concern to our modern so aptly named throw-away society.'However, by unravelling and exposing hitherto unknown facts about these delightful mammals and writing this book, he clearly indicates why we should be concerned, and leaves the reader feeling that the earth will be a sadder place if the Indus river dolphin Platanista indi becomes extinct.

Professor Pilleri points out that man is the dolphin's only enemy. Enormous barrages placed across the Indus have changed the river's environment, and the once large dolphin populations south of the barrage at Sukkur have completely disappeared. Formerly united populations have been split and the isolated dolphins can no longer migrate in search of food and/or mates. The few remaining dolphins are being exploited by the Bhutan fishermen, and to avoid this threat the author wisely proposes on-the-spot education of the fishermen and their conversion from hunters to wardens.

The book is copiously illustrated. In addition to entertaining and at times humorous descriptions of his expedition to capture specimens Professor Pilleri presents with exceptional clarity the scientific findings of his experiments with two dolphins in captivity. I highly recommend this easy-to-read book by one of the world's acknowledged authorities on cetaceans.

HORACE DOBBS

\section{Whales, by W. Nigel Bonner. Blandford, $£ 10.95$.}

How refreshing to find a thoroughly reliable and readable book on whales! Nigel Bonner uses a clear scientific approach to describe the essential mechanisms by which these mammals have become adapted to life in the sea.

Opening with an outline of the environment which they inhabit, and a brief description of each species, he goes on to describe the details of the structures and functions of the whales' bodies. The anatomical and physical requirements for swimming and diving to great depths, the role of sensory perception and the importance of sound production and reception, food preferences and feeding mechanisms are all dealt with in an admirable manner. Bonner writes as someone who knows his subject well and at first hand, and he brings into his descriptions an analytical and physical approach which is stimulating to the enquiring reader.

Chapters on reproduction, the whale brain and intelligence involve subjects which are in some ways more contentious because of the current debate over the status of the whale stocks and the ethics of hunting these animals. Bonner makes his own position 
plain on these issues after reviewing the evidence available. Although he concludes that whales are not intelligent in any special sense, he believes this is no reason to excuse the sorry way in which man has treated the whales. The history of whaling and the future for whales which he describes do not lead him to an over-optimistic conclusion. But this book by its clarity of presentation and usefulness as a major source for all the most important references on its subject could well influence that outcome by its level-headed approach.

RAY GAMBELL

\section{The Desert Bighorn, edited by G. Monson and L. Sumner. Arizona UP, Tucson, \$14.95.}

Although the description on the cover of this book implies that it is directed towards the game hunter it is in fact a collection of serious studies on the desert bighorn by 15 naturalists and biologists, and one archaeologist. Perhaps it will not hold the attention of the reader with the charm of Valerius Geist writing of his own fieldwork on the same wild sheep, Ovis canadensis. It does, however, contain much valuable information on behaviour, relationships with man and other pedators, habitat preferences, physiology, and population dynamics.

The book is dedicated to Charles Hansen, who was killed in an aeroplane accident in 1973. He had helped to plan the contents from the early 1960 s as a product of the Desert Bighorn Council, and nine of the 22 chapters were written either jointly or entirely by him. It is therefore not as up-to-date, especially the bibliography, as might be expected of a book published in 1980; nevertheless it should prove essential reading for anyone interested in the history of wild sheep in North America and their conservation today. The archaeological evidence for the hunting of bighorn sheep in the past is discussed by Campbell Grant, while the justification for its continuance today is presented by W.E. Kelly. Controlled hunting may not reduce the numbers of sheep directly, but a more insidious problem is the harmful effect of altering the ram-ewe proportions that is the result of modern hunting for trophy heads, as predicted by Geist and others. If, as Monson estimates, there is a total population of around 20,000 desert bighorn in the USA (1978 figures), this question should receive very careful monitoring.

JULIET CLUTTON-BROCK

\section{Animal Suffering; the science of animal welfare, by Marian Stamp Dawkins. Chapman, $£ 3.95$.}

Pain and suffering are positively an advantage to animals in teaching them what to avoid if they are to survive. Animals in cages, however, may not escape from such adverse experiences. What is more, we may not know what is adverse when we see it. It now seems, for instance, that separating a sheep from its herd (e.g. for shearing) is far more traumatic for it than marching the sheep plus friends into a slaughterhouse. Dr Dawkins, then, is here concerned with how to recognise mental suffering.

The fundamental problem is that, all too often, we measure animal discomfort by uninformed analogy with ourselves. Yet, as Dawkins points out, the essential differences between ourselves and other species make analogy hazardous; we would not choose to live the inverted, insectivorous life of a bat or the peptic existence of a tapeworm (to quote one of her extreme examples). So she has analysed the ways of evaluating animal suffering, and the best clues turn out to be behaviour, apparent physical health, the animal's preference, and, if it can be measured without causing suffering, physiological change.

It is a complex issue, pocked with emotionalism, misinterpretation, anthropomorphism and inadequate research, but Dawkins beats them all out and points out the pitfalls. Sometimes she beats too hard. Thus, for example, productivity as a sign of well-being is written off because to some people this means productivity of a farm rather than a single 